\title{
AEROTOXIC SYNDROME AS A MIRCE MECHANICS PHENOMENON
}

\author{
Jezdimir Knezevic* \\ MIRCE Akademy, United Kingdom
}

Aerotoxic syndrome is a somewhat controversial condition that could be triggered by the air compression systems in commercial planes. Some of the air that is compressed and recirculated throughout the cabins originates in jet engines; when excess oil molecules enter that air supply, it can result in what is called a "fume event" Thus, the main objective of this paper is to address the aerotoxic phenomenon as one possible mechnaism of the motion in Mirce Mechanic and examine how some of the existing Mirce Mechanics method could be applied to calculate reduction in the probability of inhaling aerotoxic, by the crew and frequent flyers, through the application of some of the options available to the designers and operators presented in the paper.

Key words: Smart maintenance; Proactive maintenance; Technical Diagnostics; Digitalization;

\section{INTRODUCTION}

While investigating the death of a British Airways pilot, Richard Westgate, the senior coroner in Dorset, England, Stanhope Payne, has raised concerns about aerotoxic syndrome. Mr. Westgate, a senior first officer, died in 2012 after claiming he had been poisoned by toxic cabin fumes. The coroner says that examinations of Westgate's body "disclosed symptoms consistent with exposure to organophosphate compounds in aircraft cabin air."Payne has suggested that those who spend the most time on board commercial aircraft, cabin crew and frequent travelers, could face "consequential damage to their health" because of these toxins.

Aerotoxic Syndrome is the term given to the illness caused by exposure to contaminated air in jet aircraft. The term was introduced on 20 October 1999 by Dr Harry Hoffman, Professor Chris Winder and Jean Christophe Balouet, in their report, Aerotoxic Syndrome: Adverse health effects following exposure to jet oil mist during commercial flights.

Aerotoxic syndrome is a somewhat controversial condition that could be triggered by the air compression systems in commercial planes. Some of the air that is compressed and recirculated throughout the cabins originates in jet engines; when excess oil molecules enter that air supply, it can result in what is called a "fume event" Thus, the main objective of this paper is to address the aerotoxic phenomena as one possible mechnaism of the motion in Mirce Mechanic and examine how some of the existing Mirce Mechanics method could be applied to calculate reduction in the probability of inhaling aerotoxic, by the crew and frequent flyers, through the application of some of the options available to the designers and operators presented in the paper.

\section{CABIN PRESSURISATION}

Naturally, atmospheric pressure around the earth reduces with altitude. Consequently, humans can tolerate a reduction in oxygen partial pressure up to around 10,000ft. Beyond that oxygen partial pressure reduces rapidly and impairs brain function. To provide safe and pleasant flights, the maximum certified cabin altitude in normal operation is $8,000 \mathrm{ft}$.

During flight, air is derived from the compression stage of the jet engine. This bleed air is conditioned and filtered, with an exchange of 10-15 times per hour with outside air and 20-30 times per hour including outside and filtered recirculated air.

\section{HUMAN TOXICOLOGY}

In order for a toxic effect to occur chemicals foreign to the human body must be absorbed from the surrounding environment and transported to the relevant site in the body. Routes of entry include ingestion, skin absorption and inhalation 
with sufficient concentration for the chemical to cross the many cell membranes. In the case of inhalation, the absorption of the chemical will depend on the percentage partial pressure it exerts within the total pressure in the lung alveoli as well as its solubility. The human senses, particularly smell, are generally effective in detecting potentially hazardous substances at a level well below that which causes harm (the major exception being carbon monoxide). For most volatile organic compounds, the normal detection level is around 1,000 times less than the level that is likely to harm health.

For organophosphates, exposure to sufficient doses of the ortho isomer may cause adverse effects on the nervous system, including impairment of neuromuscular and peripheral nerve synapse function, but not brain cognitive function. The majority of cases recorded in the medical literature since 1943 have been associated with swallowing contaminated food or drink, and reports of occupational intoxication are rare with no cases due to inhalation.

There are legal exposure limits for hazardous substances at work, the Indicative Occupational Exposure Limit Values (IOELVs); for the ortho isomers ToCP, the workplace limit is $0.1 \mathrm{mg} / \mathrm{m}^{3}$ for 8 hours with an emergency short-term limit of $0.3 \mathrm{mg} / \mathrm{m} 3$ for 15 minutes. From knowledge of aviation respiratory physiology, it can be shown that these values remain valid up to a cabin altitude of 8,000ft [03].

\section{PHYSIOLOGY OF BREATHING}

The total pressure in the lung alveolus is the sum of the partial pressures of all the gases in the mixture, and the transfer of any gas across the alveolar membrane depends on the properties of the membrane and the partial pressure exerted by that gas within the mixture.

Oxygen and carbon dioxide are exchanged in the alveoli; the partial pressure of oxygen is higher in the air than in the blood so it combines with haemoglobin to be carried to the tissues, whereas carbon dioxide is at a higher partial pressure in the blood so is given up to the alveolar air. It is important to stress that it is partial pressure of the concentration that drives the exchange. There is water vapour in the alveoli as well as oxygen, carbon dioxide and nitrogen, and while the partial pressures of the atmospheric gases fall with increasing altitude, the water vapour pressure remains constant as a result of metabolism. As alveolar absorption is governed by Dalton's Law of partial pressures, as well as Fick's Law, and the partial pressure of bleed air contaminants is a very small proportion of the total alveolar gas pressure, it is reducing rapidly.

\section{TOXIC AIRCRAFT MATERIALS}

Aircraft materials such as jet-fuel, de-icing fluids, engine oil, hydraulic fluids, and so on, contain a range of ingredients, some of which can be toxic. Although these chemicals are usually retained in engines and equipment into which they have been added, they can sometimes find their way into cabin air where crew and passengers are located, through incidents such as engine oil leaks, seal failures and fluid ingestion by Auxiliary Power Unit (APU). Further, operational activities, such as APU "pack" burnouts, can give rise to significant contamination. Dozens of in-cabin leak/smoke events are documented annually often correlated to aircraft fluid leak events.

Fume events are much more frequent, correlated to less important aircraft fluid leaks (hundreds per year), or to other independent sources. In total, aircraft fluid leak/fume/smoke events are estimated to impact over 300 flights per year worldwide, resulting in exposures to an estimated 40,000 or more crew and passengers. Some models of airplanes appear to be particularly prone to leaks.

The range of bleed air contaminants and their concentrations, which may be found during incabin contamination events during flight, can be extensive. Significant contaminants include: carbon monoxide, aldehydes; aromatic hydrocarbons; aliphatic hydrocarbons; chlorinated, fluorinated, methylated, phosphate, nitrogen compounds; esters; and oxides. One additional problem is the lower oxygen concentration operating in the cabins of planes flying at altitude.

Inhalation is an important route of exposure, with exposure to uncovered skin being a second, less significant route (for example, following exposure to oil mists) and ingestion improbable.

In terms of toxicity, a growing number of crew are developing symptoms following both short term and long term repeated exposures. Neurotoxicity is a major flight safety concern, especially where exposures are intense. 


\section{HISTORY OF THE PROBLEM}

The first well-documented case was of a aerotoxicity was recorded in 1977 when the C-130 Hercules navigator became incapacitated after breathing contaminated cabin air in. However, the neuro-toxic properties of organophosphates have been known about since before the Second World War. The toxicity of heated jet oil was known from 1954.

UK Committee on Toxicity of Chemicals in Food, in 2007 report, produced by the in Consumer Products and the Environment, stated that fume events occur on average in 1 flight out of 100 . However, on some aircraft types crews report that they experience fumes to some degree on every flight. However, as the definition of "fume event" is not agreed upon, it makes it impossible to get the real picture of the problem.

\section{CAUSES OF CABIN AIR CONTAMINATION}

In order to have a comfortable environment and sufficient air pressure to breathe at the altitudes at which jet airliners fly, a supply of warm compressed air is required.

This is nowadays supplied direct from the jet engines and is known as 'bleed air', with the sole exception of the new Boeing 787. It is mixed inside the aircraft with recirculated cabin air at a ratio of 50/50. Although some of the air is subsequently recirculated, all of the air originates from the jet engines.

Bleed air comes from the compressor section of the jet engine, which has to be lubricated. Jet engines mostly have "wet seals" to keep the oil and air apart, which cannot be $100 \%$ effective. Furthermore, these seals, like any mechanical component, slowly wear out and their effectiveness gradually declines. This wear can occur more rapidly when the engine is working hard, such as climbing under full throttle. They may also fail suddenly and will then let a significant amount of oil into the very hot compressed bleed air, resulting in fumes and/or smoke entering the cabin. This is known as a "fume event". There are no filters in the bleed air supply to stop this happening.

It is necessary to stress that the oil used to lubricate jet engines is not based on petroleum hydrocarbons, as are lubricants for internal combustion engines used in motor cars, outboard motors, tractors etc. As jet engines operate at much higher temperatures they use special synthetic chemicals as oil. They also contain organophosphate additives as antiwear agents and other aromatic hydrocarbons as antioxidants. Some of the oil gets partially decomposed, i.e. chemically altered due to the high temperatures in the engine. Thus, the contamination is composed of the "oil", the additives, and the decomposition products. The last two of these three generates the harmful toxicity.

Materials used in the operation of aircraft may contain hazardous ingredients, some with significant toxicities, and need care in handling and use. Some maintenance or operational activities, such as leaks or poorly controlled maintenance procedures, can, through contamination of aircraft cabin air, produce unwanted exposures to personnel and passengers.

\section{DETECTION OF AEROTOXIC}

Slight leakage of oil into the cabin may be detected by smell. Descriptions such as 'sweaty socks', 'wet dog', 'vomit', 'sweet oily smell' have been used to describe it. Background levels of contamination may not be detectable by smell. If a "fume event" occurs bluish haze or smoke in the cabin may be visible. Only visible smoke is officially reported in the flight log, leading to under-reporting of the actual frequency. There are no chemical sensors in modern jet aircraft. The noses of the aircrew are the only detectors at the moment.

The degree of contamination depends on jet engine type and how recently it was serviced, among other factors. There are few reliable measurements but based on what has been documented it is possible to estimate that about a quarter of flights suffer slight but significant contamination. It is important to remember that this contamination might be continuous throughout a flight; hence the total exposure might end up as much as after a brief fume event.

Swab-testing confirms that fume events also deposit substantial residues on all the interior surfaces of the cabin, including the skin of those aboard.

The amount of leakage may increase due to faulty maintenance (including during the interval immediately preceding a scheduled maintenance intervention). If there is actual failure of a component of the seal, leakage may be considerable.

In any case, leakage tends to be greater when 
the engine is cold and when the engine is working hard. Furthermore, some oil is pyrolysed in the engine, and the complex mixture of pyrolysis products may also be present in the bleed air. Tricresyl phosphates are potent neurotoxins.

\section{AEROTOXIC SYMPTOMS}

Symptoms have been collected from ten cases of pilots, first officers, pursers and flight attendants, flying in five airlines, three models of airplane and in four countries. The only common feature is that at some stage, they were involved in an incident where a leak of oil mist to the flight deck or passenger cabin occurred. Symptoms were reported from single exposures to elevated exposures and from long term low level exposures to low level oil leaks or residual problems from previous contamination. Symptoms from single or short term exposures include: blurred or tunnel vision, disorientation, memory impairment, shaking and tremors, nausea/vomiting, parasthesias, loss of balance and vertigo, seizures, loss of consciousness, headache, lightheadedness, dizziness, confusion and feeling intoxicated, breathing difficulties (shortness of breath, tightness in chest, respiratory failure), increased heart rate and palpitations, nystagmus, irritation (eyes, nose and upper airways).

Consequently, due to all of the above listed physical and psychological manifestations, the phenomenon described through the term 'syndrome' is used. Many general medical practitioners are unaware of Aerotoxic Syndrome and may diagnose sufferers with illnesses such as psychological or psychosomatic disorders.

Although some of these disorders may form part of Aerotoxic Syndrome, such part-diagnoses on their own miss the root cause of the problem, which is exposure to toxic oil components in a confined space. Furthermore, any misdiagnosis is likely to lead to inappropriate treatments, which may make the condition even worse.

Aviation medicine specialists are aware of the problem but Aerotoxic Syndrome does not seem to have gained official acceptance among the majority of them. Hence, despite (or because of) their expert knowledge they are likely to seek other explanations and there are plenty of neurological symptoms associated with aviation that have nothing to do with inhaling oil.

As the toxins attack the central nervous system, including the brain, it's not easy to predict how dif- ferent exposures may affect different people, due to the genetic variability of individuals. Hence, one person's body may have less success than another's at detoxifying contaminants and so be affected after just one flight, whilst others may be unaffected after years of exposure. Depending on detoxifying efficiency, the adverse health effects may be cumulative. Therefore, anyone frequently flying, which means once or more a week, is repeatedly exposed and is therefore especially at risk.

\section{MIRCE MECHANICS IMPACT OF AEROTOXIC SYNDROME}

Aerotoxic syndrome presents significant issues regarding the health of pilots, cabin crew and passengers, but most notably with regard to safety if pilots are incapacitated and cabin crew cannot supervise cabin evacuations during emergencies. Health effects include short-term irritant, skin, gastrointestinal, respiratory and nervous system effects, and long term central nervous and immunological effects. Some of these effects are transient, while others appear more permanent. The exacerbation of pre-existing health problems by toxic exposures is also highly probable. Thus, the aerotoxic syndrome has potential to generate a failure of commercial aviation flights and such has impact of functionability performance of maintainable systems.

In the past, safety systems have focused on the prevention and alleviation of accidents. Having achieved a largely accident-free state, attention can now turn to ensuring wellbeing to flight crew and frequent flyers passengers. Thus, some of the existing Mirce Mechanics method could be applied to calculate reduction in the probability of inhaling aerotoxic, by applying some of the following options that are available to the designers and operators of passengers' aircrafts [9]:

1. Eliminate toxic components from jet oil. Although this was tried, it is proving remarkably difficult to achieve the same high-temperature antiwear properties. Recent progress in understanding the molecular mechanisms of antiwear action gives grounds for some optimism

2. Incorporate filters or adsorbents in the air line between the bleed off the engine and the entry into the cabin. One problem with this approach seems to be that the existing spectrum of technologies are designed either to 
eliminate dust using through micro-porous membranes, or to eliminate small molecules via adsorption on the surface of a substance with a high specific surface area and broad nonspecific affinity. Another problem is that both filters and adsorbents become saturated and, therefore, need regular replacement

3. Eliminate bleed air by compressing the air using a separate compressor, as it was achieved on early jet airliners such as the Vickers VC10. However, the same approach is used during the design of the latest Boeing 787 "Dreamliner". There may be additional reasons for doing this, such as the need to eliminate flows of hot air through a structure incorporating many novel composite materials.

4. Screen aircrew and passengers for susceptibility to organophosphate poisoning. It would appear that susceptibility is genetically determined; it depends on the available and potentially available variety and quantity of cytochrome P450 enzymes in the liver. There are possibly different degrees of susceptibility, according to which the occupational risk, or risk from frequent flying, may be too great or even a single flight might constitute an unacceptably high risk of health damage.

5. Retrofit sensors for continuously monitoring chemical contamination of the cabin atmosphere. There is already a considerable literature on measuring aerotoxic contamination, and even a personal sensor has been proposed. Given the general needs for noninterference with aircraft control systems and miniaturisation, integrated optical nano-sensors would appear to be called for. Sensors should be provided in the bleed air ducts and at various points in the cockpit and passenger compartments. The sensors would firstly provide an objective physicochemical indication of the presence of contamination, and secondly they would provide information to guide the captain in deciding what action to take

6. Educate aircrew more comprehensively about the issue, especially so that they recognise the symptoms of incipient oil seal problems and can promptly take appropriate action like: donning oxygen masks, landing at the next available aerodrome, ordering passengers to don activated carbon masks and so forth.
7. Issue activated carbon masks, preferably with filtration or adsorption capability, to all passengers, to be donned should a "fume event".

8. Facilitate prompt reporting of any suspected oil leakage into the cabin so that appropriate engine maintenance can be carried out without delay. In addition, the development of biomarkers for intoxication, which will assist prompt diagnosis and the application of appropriate therapy to passengers and aircrew having experienced a fume event.

\section{CONCLUSION}

Research performed at the MIRCE Akademy, has shown that the direct exposure to hydraulics and lubricants are toxic, potentially causing effects such as blurred vision, disorientation, memory loss, lack of coordination, nausea that if they occurred in flight crew, are direct threats to flight safety. Further, there is factual evidence that flight deck, cabin crew and passengers can be directly exposed to trace chemicals on aircraft in sufficient concentrations to cause acute, immediate to long term symptoms.

These exposures can produce symptoms of toxicity. Symptoms associated to the aerotoxic syndrome clearly include neurotoxicity as neuropsychological effects, as well as other symptoms typically correlated to chemical intoxication. Links between neurotoxic effects and certain contaminants known to be neurotoxic, such as the phosphate esters, are suspected.

Aerotoxic syndrome presents significant issues with regard to the health of pilots, cabin crew and passengers, but most notably with regard to air safety if pilots are incapacitated and cabin crew cannot supervise cabin evacuations during emergencies. Health effects include short-term irritant, skin, gastrointestinal, respiratory and nervous system effects, and long term central nervous and immunological effects. Some of these effects are transient, while others appear to be more permanent. The exacerbation of preexisting health problems by toxic exposures is also highly probable.

While in the past, flight safety systems have focused on the prevention and alleviation of accidents, which have achieved a largely accidentfree flights, the attention should be turned now to creation of healthy flying environment for pilots, cabin crew and frequent flyers passengers. 
Thus, some of the existing Mirce Mechanics method could be applied to calculate reduction in the probability of inhaling aerotoxic, by applying some of the options available to the designers and operators presented in the paper.

\section{ACKNOWLEDGMENT}

I wish to dedicate this paper to the memory of Professor, Dr Jovan Todorovic (1932-2016)., who introduced me to the subject of System Reliability and Effectiveness, in the Faculty of Mechanical Engineering at Belgrade University in the late 1970's, and then he mentored me during the Master and Doctoral studies. Our last scientific collaboration was through the publications of my research papers in this Journal where he was Editor in Chief, until his death in May this year.

\section{REFERENCES}

1) Todorović, J.: Upravljanje održavanjem na bazi rizika, (2009) Journal of Applied Engineering Science (Istraživanja i projektovanja za privredu, no. 1, p. 23-33.

2) Winder C., Balouet, JC, Aerotoxic Sydrome: Adverse Health Effects Following Exposure to Jet Oil Mist During Commercial Flights, Eddington, I, editor. Towards a safe and Civil Society, Proceedings of the International Congress on Occupational Health Conference, held in Brisbane, Australia, 4-6 September 2000. ISBN 0646401546

3) Ernsting J, Ward J, Rutherford OM. Cardiovascular and respiratory physiology. In
Rainford DJ, Gradwell DP (eds). Ernsting's Aviation Medicine 4ed (2006) ISBN-10 0340 81319 9: 13-40

4) Mobil Jet Oil II. Materials Safety Data Sheet. ExxonMobil (2008).

5) Rudnick, L.R. (ed.). Synthetics, Mineral Oils, and Bio-Based Lubricants. Chemistry and Technology. Boca Raton (Fla.): CRC (Taylor \& Francis) (2006).

6) The Manufacture and Use of Selected Aryl and Alkyl Aryl Phosphate Esters. Report EPA 560/6-76-008. Washington, D.C.: US Environmental Protection Agency (1976).

7) Kamanyire, R. and Karalliede, L. Organophosphate toxicity and occupational exposure. Occupational Medicine, (2004) 69-75.

8) Abou-Donia, M.B. Organophosphorus esterinduced chronic neurotoxicity. J. Occupational Health Safety (Australia \& New Zealand) (2005) 408-43

9) Ramsden, J. J., The scientific adequacy of the present state of knowledge concerning neurotoxins in aircraft cabin air, Collegium Basilea \& AMSI, doi: 10.4024/27RA11A. jbpc.11.04, Journal of Biological Physics and Chemistry, 11, (2011) 152-164

Paper sent to revision: 23.09.2016.

Paper ready for publication: 15.12.2016. 